\title{
AVANCES DE LA FRUTICULTURA EN MÉXICO'
}

\author{
ANGEL VILLEGAS MONTER ${ }^{2} \&$ ANTONIO MORA AGUILERA ${ }^{3}$
}

RESUMEN - Las estadísticas oficiales informaron que en 2008 se cultivaron 264944 ha con valor de la producción de \$ 14741 millones de pesos, en 20 frutales de clima templado; mientras que, en 35 tropicales y subtropicales fue de 1822748 ha con valor de $\$ 43463$ millones de pesos. De los 55 frutales, sólo naranjo (Citrus sinensis), mango (Mangifera indica), Aguacate (Persea americana), limón mexicano (C. aurantifolia), banano (Musa acuminata), lima persa (C. latifolia) y manzano (Malus domestica) se cultivan más de 50000 ha, lo que explica porque es limitada la oferta de frutas en las grandes ciudades (Distrito Federal, Monterrey, Guadalajara, Puebla, Veracruz, entre otras). Considerando que el 79,27\% de la superficie plantada con frutales tropicales y subtropicales es de temporal, las densidades de plantación son bajas, la propagación de plantas no se hace en viveros certificados (sólo cítricos), los rendimientos son bajos en comparación con otros países productores. Por otra parte, debido a la falta de técnicos capacitados, en los últimos 28 años la demanda de fruta se ha solucionado incrementando la superficie plantada, pero los rendimientos han disminuido. La presencia de nuevas enfermedades; Huanglongbing, Meleira, Sunblotch, plantean nuevos retos y también posibilidades si utilizamos los avances tecnológicos. La fruticultura es una alternativa viable pero deben utilizar altas densidades, árboles de porte bajo, plantas de origen genético conocido y calidad fitosanitaria probada que permitan tener mayores rendimientos y con ello competitividad.

Terminós para indexación: Fruticultura, Producción, mango, cítricos, aguacate, papaya.

\section{ADVANCES IN MÉXICO FRUITCULTURE}

\begin{abstract}
Official statistics in 2008 indicate that 20 species of temperate climate fruit trees were cultivated in 264944 ha and the production value was \$14 741 million pesos; while 35 species of tropical and subtropical fruits were cultivated in 1822748 ha and the production value was $\$ 43463$ million pesos. Of the 55 fruit trees, only orange (Citrus sinensis), mango (Mangifera indica), avocado (Persea americana), Mexican lime (C. aurantifolia), banana (Musa acuminata), Persian lime (C. latifolia), and apple tree (Malus domestica) were cultivated in more than 50000 ha, it explains why the supply of fruits in large cities (Mexico City, Monterrey, Guadalajara, Puebla, Veracruz, among others) is limited. Thinking about that $79,27 \%$ of the tropical and subtropical fruit planted area is rain fed; plant propagation is not grown in certified nurseries (only citrus trees), the plantation densities and yields are lower than others producing countries. Moreover, due to the lack of specialists, in the last 28 years the fruit demand has been solved by increasing the planted area, but yields have decreased. The new diseases; huanglongbing, Papaya meleira, Sunblotch, create the necessity of challenges and opportunities, if we use technological advances. If we use high density, dwarf trees, plants of known genetic origin and phytosanitary quality, which allows having higher yields and thus competitiveness, fruit crops could be a viable alternative.
\end{abstract}

Index terms: Fruit crops, production, mangoes, orange, avocado, papaya.

\footnotetext{
${ }^{1}$ Palestra Sinfruit 103 - Simpósio Internacional de Fruticultura - Avanços na Fruticultura (17 a 21 Outubro)

${ }^{2}$ Profesor Investigador Titular, PREGEP-Fruticultura, Campus Montecillo, Colegio de Postgraduados. Km 36.5 carretera México-Texcoco, CP. 56230, Texcoco, Edo de México. México. E-mail villema53@hotmail.com

${ }^{3}$ Profesor Investigador Adjunto, Postgrado en Fitosanidad -Fitopatología, Campus Montecillo, Colegio de Postgraduados. Km 365. Carretera México-Texcoco, CP 56230. Texcoco Edo de México. México. E-mail aguilera@colpos.mx
} 


\section{INTRODUCCIÓN}

El territorio mexicano se ubica entre los paralelos $14^{\circ} 30^{\prime}$ y $32^{\circ} 43^{\prime}$ de latitud norte y los meridianos $86^{\circ} 42^{\prime}$ y $118^{\circ} 27^{\prime}$ de longitud oeste. De las 195.8 millones de hectáreas que tiene el país, 24 millones $(12 \%)$ se consideran aptas para la agricultura, 105 millones (54\%) para la ganadería, 50 millones (26\%) para actividades forestales y los 16.8 millones restantes ( $8 \%$ ) para usos diversos (Lépiz y Rodríguez, 2006).

Aún cuando se desconoce el número exacto de especies que integran la flora nativa mexicana, las estimaciones van desde 20,000 (Rzedowsky, 1998) hasta 30,000 (Ramírez et al., 2003). Para 2003, en las estadísticas agrícolas nacionales se tenían registros de 50 especies autóctonas, de las cuales 24 corresponden a cultivos anuales y 26 a plantas perennes (Lépiz y Rodríguez, 2006). Por otra parte, Borys y Leszczyñska - Borys (2001), señalan que en México se explotan con fines comerciales 32 especies nativas, 14 cuyo actividad aún no se refleja en las estadísticas y 620 especies que se cultivan localmente en huertos familiares o son de recolección. Las referencias anteriores muestran la riqueza en Recursos Fitogenéticos que tiene México, que debemos preservar y explotar.

Del total de superficie cultivada en México en 1980 (16 039480 ha), el 1,14\% correspondía a frutales de clima templado y $6,55 \%$ a frutales tropicales y subtropicales, para 2008 la superficie se incrementó hasta 20502833 ha, de las cuales 1,29\% eran frutales de clima templado y 8,89\% (Cuadro 1). De 1980 a 2008 la superficie cultivada se ha incrementado $27,8 \%$, la de frutales de clima templado $18,8 \%$ y en frutales tropicales y subtropicales $73,4 \%$. De la superficie plantada en 2008 con frutales de clima templado (264 944 ha), el 60,94\% era de riego; mientras que en frutales tropicales y subtropicales (1 822748 ha) fue únicamente el $20,73 \%$, esto explica en parte porque los rendimientos no se han incrementado, aún cuando la superficie aumentó en $661 \%$ en 28 años.

Del total de frutales que reportan las estadísticas; 20 corresponden a clima templado, sobresalen en este grupo manzana (Malus domestica) con 55000 ha, tuna (Opuntia spp) 45974 ha, Durazno (Prunus persica) 40252 ha, uva (Vitis vinifera) 26547 ha y ciruela (Prunus domestica) 14436 ha. Se incluyen datos de 35 frutales tropicales y subtropicales; destacan aguacate (Persea americana), 112478 ha, mango (Mangifera indica), 172284 ha, naranja (Citrus sinensis), 338336 ha, banano (Musa acuminata), 77 705 ha, lima persa (C. latifolia), 55763 ha, limón mexicano (C. auratifolia), 87937 ha, guayaba (Psidium guava), 21497 ha, Pomelo (C. paradisi), 17412 ha, Piña (Ananas comosus), 17079 ha, papaya (Carica papaya), 16157 ha y mandarina (C. reticulata), con 15977 ha, integran las 16 especies que se cultivan en mayor proporción y representan más del $95 \%$ de la superficie plantada con frutales en México, la limitada oferta de frutas muestra la necesidad de incrementarla y que la fruticultura es una excelente alternativa para los productores.

Considerando que México es el principal exportador de aguacate, mango, lima persa y papaya, presentaré un breve análisis de estos frutales y al final señalaré algunos aspectos generales de la fruticultura.

\section{Aguacate (Persea americana)}

En 2008 se cosecharon 112478 ha de aguacate 'Hass', 'Criollo' y sin clasificar (SIAP, 2010), de las cuales sólo 42,59\% es de riego. La evolución de la superficie cultivada en el periodo 1980-2008, se muestra en la Figura 1, donde se observa un incremento $206 \%$ en 28 años, lo que muestra el dinamismo que ha tenido esta especie en México, donde se consumen más de $9 \mathrm{~kg}$ de fruta per cápita (Teliz y Marroquín, 2007), por lo que la demanda interna es elevada. Durante el periodo evaluado el rendimiento disminuyó de 8106 a 7022 kg.ha -1, lo anterior se puede deber a que las plantaciones cada vez se establecen a mayor altitud en zonas limítrofes para el cultivo, también a que los árboles son de porte elevado y hay problemas de sombreado. Cabe indicar que en Michoacán se cultiva el $80 \%$ de la superficie total de México y en tres municipios (Uruapan, Tancitaro y Peribán), el 50\% del mencionado estado. Entre los problemas que presenta destacan árboles de porte alto que dificultan la cosecha y otras labores del cultivo, no utilizar portainjertos clonales tolerantes a phythophtora, incremento de Sunblotch en las plantaciones debido a que no hay viveros certificados. Otro aspecto que se tiene que atender, es diversificar el uso de cultivares dado que más del 97\% de la superficie esta plantada con 'Hass'.

\section{Mango (Mangifera indica)}

La superficie cultivada con mango en 1980 fue de 63736 ha y para 2008 de 172284 ha (Figura 2), lo que representa $369 \%$ de incremento, pero sólo el $36,23 \%$ de la superficie es de riego y el rendimiento es de 10 t.ha -1 aproximadamente, que es inferior al de Brasil y otros países productores de mango, debido a lo anterior, la competitividad de México a nivel internacional es limitada. Desde 2002, el SIAP presenta la información desglosada por variedad, en 
el Cuadro 2, se muestra la dinámica de crecimiento de los principales cultivares destacan 'Manila' y 'Ataulfo' (poliembriónicos) con 77292 y 'Haden', 'Kent', 'Keit' y 'Tommy Atkins' (monoembriónicos) con 63401 ha. El hecho de que se cultiven cultivares de pulpa amarilla, muestra la preferencia de los consumidores hacia ese tipo de fruta. Los "Petacones" como se le denomina en México a los monoembriónicos son básicamente para exportación. Cabe indicar que 'Ataulfo' es el cultivar que más ha crecido en superficie en los últimos años, también es empleada para exportación.

Entre 2002 y 2008 la superficie total de mango se incrementó $106 \%$, pero en los principales cultivares fue de $246,565,159,283,110$ y $345 \%$ para 'Ataulfo', 'Haden', 'Keit', 'Kent', 'Manila' y 'Tommy Atkins' respectivamente. Considerando el rendimiento promedio nacional (10 t.ha-1), se puede concluir que la demanda se ha atendido aumentando la superficie cultivada y no el rendimiento, que es una alternativa más rentable, por lo que se deberían implementar prácticas para revertir lo anterior, considerando la importancia de este cultivo para los exportadores.

Los principales problemas que tiene el cultivo de mango son: árboles de porte alto, bajas densidades de plantación, estacionalidad de la producción en los meses de mayo, junio y julio, mosca de la fruta y la falta de viveros certificados que garanticen el origen genético y calidad fitosanitaria del material vegetativo.

\section{Lima persa (C. latifolia)}

Considerando que en México se cultivan 545 000 ha de cítricos y que la mayoría de los problemas son comunes para todas las especies, es importante considerar los cambios que ha tenido la citricultura en el País debido a la presencia de enfermedades. En 1982 se detectó por primera vez el virus de la tristeza de los cítricos (VTC) en Tamaulipas, posteriormente en 1986 se detectó en Veracruz, en ambos casos, las plantas enfermas se erradicaron, a pesar de lo anterior, en 1992 nuevamente se volvieron a detectar plantas positivas en vivero que también fueron eliminadas. Con base en lo anterior, en agosto de 2001 se publicó la NOM-031-FITO-2000, "Por la que se establece la campaña contra el virus tristeza de los cítricos", en ella se indica que no se debe utilizar el naranjo agrio (C. aurantium) como portainjerto, con excepción de limón mexicano. En 2002 se publica la NOM-079-FITO 2002, "Requisitos fitosanitarios para la producción y movilización de material propagativo de cítricos libre de virus tristeza y otros patógenos asociados a cítricos", en ella se establecen los requisitos para la certificación de Bancos de Germoplasma, Lotes Productores de Yemas, Huertas Productoras de Semilla y Viveros para la producción de plantas certificadas, este hecho es significativo para la fruticultura en México, debido a que para junio de 2011 se tienen 24 viveros certificados con capacidad para producir 7,1 millones de plantas de cítricos (SENASICA, 2011). Actualmente en México se ha detectado la presencia de VTC en 20 de los 23 estados productores de cítricos y el pulgón café se encuentra en 10 estados.

Otro hecho importante lo significó la detección de Leprosis de los cítricos en plantas de traspatio durante 2004 en Chiapas, en 2006 en Tabasco en huertos comerciales, en ambos estados se decretó la cuarentena y se han eliminado más de 100000 árboles (SENASICA, 2010) y en marzo de 2010 se detectó en las Choapas, Veracruz, al sur del principal estado productor de cítricos en México.

El cambio más importante para la citricultura en México se dio el 6 de junio de 2009, cuando en Tizimin, Yucatán, se detectaron las primeras plantas positivas a Huanglongbing (HLB), el 18 de agosto del mismo año en Chiquila, Quintana Roo, el 1 de diciembre, en Bahía de Banderas, Compostela y San Blas, Nayarit y Puerto Vallarta, Jalisco. El 17 de marzo de 2010 en Calakmul, Campeche, posteriormente en Colima, Sinaloa y Michoacán, en marzo de 2011 en Chiapas, por lo que en junio de 2011 el HLB está presente en nueve estados productores de cítricos. La presencia de enfermedades causadas por virus y bacterias en cítricos, cambia el panorama de la citricultura en México, donde será necesario tener productores capacitados dispuestos al cambio ¿Qué significa?. Utilizar plantas de cítricos de viveros certificados, emplear altas densidades de plantación, eliminar plantas con síntomas de HLB, así como otras prácticas de manejo, (riego, fertilización, control oportuno de plagas, etc.), para tener mayores rendimientos desde los primeros años y considerar que la vida comercial de las plantaciones será menor.

El panorama anterior también afecta la producción de Lima Persa, donde debido a la presencia de Wood pocket, en campo se pueden confundir los síntomas de HLB. Aún cuando Lima Persa se cultiva en México desde 1982, las primeras estadísticas se reportaron hasta 1996, antes de ese año, la superficie era considerada junto con limón mexicano $(C$. aurantifolia). Desde 1996 hasta 2008 la superficie de lima persa se ha incrementado $427 \%$, lo que muestra la dinámica de crecimiento de esta especie que es principalmente de exportación (Figura 3). A pesar de lo anterior, la superficie de temporal es de $81,51 \%$, 
lo que explica en parte el rendimiento promedio nacional de 14,94 t.ha-1. Como se indicó, a diferencia de aguacate y mango, en cítricos la mayoría de los productores utiliza planta certificada. Es importante señalar que debido a la presencia de Huanglongbing, a partir de 2010 la producción de plantas de cítricos se hace en espacios protegidos.

Unos de los principales portainjertos utilizados en lima persa fue el Limón Volkameriano $(C$. volkameriana), debido a la calidad de frutos que produce (rugosos, verde oscuro), sin embargo en los últimos años los productores prefieren ' $\mathrm{C} 35^{\prime}$ y 'Citrumelo Swingle', lo anterior puede estar relacionado con el tipo de poda que utilizan en Martínez de la Torre, Vera Cruz, principal municipio productor de lima persa en México, donde eliminan la copa del árbol para manejarlo como seto, de esta forma disminuye la producción de frutos en racimo y se estimula la de frutos individuales más expuestos al sol (Rivera-Cabrera et al., 2010).

La mayoría de las plantaciones tienen Caquexia, Exocortis y Wood pocket, estas enfermedades se acentúan por la falta de cuidados en la poda, que en la mayoría de los casos es mecánica. Debido a lo anterior y a la presencia de gomosis causada por Phythophtora sp., las plantas mueren a partir de los seis años, por lo que en este cultivo se tiene la cultura "del replante". La estacionalidad de la producción en los meses mayo, junio y julio, es otro problema que se ha tratado de resolver por medio de prácticas para favorecer la producción de invierno (enero, febrero, marzo), sin que se tengan los resultados deseados.

\section{Papaya (Carica papaya)}

El virus de la mancha anular (VMA) se identificó en México en 1975, entre 1987 y 1994 se confirmó su presencia e incidencia en los principales estados productores (Veracruz, Chiapas, Yucatán). Eso explica la reducción en la superficie cultivada entre 1980 y 1990 (Figura 4). Después de los primeros años de incertidumbre donde se suponía que el cultivo desaparecería debido a la presencia del VMA, los productores que adoptaron la nueva tecnología que consistió en lo siguiente: el cultivo paso de ser perenne a prácticamente anual, se inicio el uso del cultivar 'Maradol' que prodoce frutos de tamaño medio y tolera el manejo postcosecha, utilizan semilla certificada, la producción de plántula (viveros) se hace en espacios protegidos, se incrementó la densidad de plantas por hectárea (2 200 plantas), se utilizan plantas hermafroditas, se eliminan las plantas con síntomas de VMA, la mayoría de las plantaciones tienen sistema de riego, se incrementó el uso de agroquímicos, lo anterior trajo como consecuencia que se incrementaran los rendimientos, antes de VMA la producción promedio era de 35 t.ha-1, después de VMA más de 80 t.ha-1,este es un excelente ejemplo que valdría la pena considerar para otros casos. Para evitar problemas con antracnosis en Veracruz, México, se cosecha de enero hasta junio, cuando inicia el periodo de lluvias luego se elimina la plantación debido a que se incrementan los costos de producción y el cultivo ya no es rentable. Entre los problemas que presenta el cultivo están el uso excesivo de plaguicidas, más del $95 \%$ de la superficie se cultiva con 'Maradol', es necesario el empleo de nuevos cultivares de pulpa roja de menor tamaño (1 $200-1500 \mathrm{~g}$ ), algunos productores empiezan a producir su semilla y en 2009 se detectó en Quintana Roo la presencia del virus meleira, que será un nuevo reto para los productores.

Son diversos los problemas que presenta la fruticultura en México, con excepción de cítricos, la producción de plantas no se hace en viveros certificados, en consecuencia hay problemas fitosanitarios $\mathrm{y}$ de origen varietal. El uso de portainjertos clonales seleccionados es limitado, en durazno, mango, aguacate, y frutales nativos (anonáceas, sapotáceas, crataegus, etc.) se utilizan principalmente portainjertos "criollos" (semillas de plantas de origen desconocido de la misma especie), regularmente colectados en campo sin cuidados fitosanitarios. Con excepción de Manzano, Uva y Papayo, donde la mayoría de la superficie es de riego, en los demás frutales la mayor proporción es de temporal. El principal destino en los frutos de exportación (Aguacate, Mango, Lima Persa, Papaya y Uva) es Estados Unidos, por lo que es necesario diversificar el mercado para evitar problemas. En general los productores no están organizados esto trae como consecuencia problemas de comercialización dado que se hace por medio de intermediarios. Otro problema serio es la falta de mejoramiento genético, con excepción de mango 'Ataulfo', las principales especies que se explotan son introducidas y estamos en espera de nuevos materiales, esto limita la competitividad debido a que no generamos materiales de acuerdo a las necesidades del mercado nacional e internacional. Aunado a lo anterior, la falta de personal capacitado en frutales tropicales, limita la aplicación de nuevos paquetes tecnológicos que permitan incrementar los rendimientos, lo que ha impedido que se consolide la fruticultura. 
CUADRO 1- Superficie total y cultivada con frutales templados, subtropicales y tropicales, en México $(1980-2008)$.

\begin{tabular}{|l|c|c|c|c|}
\hline Cultivo & 1980 & 1990 & 2000 & 2008 \\
\hline Frutales templados & 231757 & 248052 & 276007 & 264944 \\
\hline $\begin{array}{l}\text { Subtropicales y tro- } \\
\text { picales }\end{array}$ & 1050917 & 1224362 & 1662992 & 1822748 \\
\hline Total & 16039480 & 17830949 & 18734050 & 20502833 \\
\hline
\end{tabular}

Fuente: Servicio de Información y estadística Agroalimentaria y Pesquera (SIAP). Anuario Estadístico de la Producción Agrícola de los Estados Unidos Mexicanos. Secretaría de Agricultura, Ganadería, Desarrollo Rural, Pesca y Alimentación. 1980-2008.

CUADRO 2 - Superficie plantada con las principales variedades de mango (Mangifera indica) en México $(2002-2008)$.

\begin{tabular}{|l|r|r|r|r|}
\hline Variedad & \multicolumn{1}{|c|}{2002} & \multicolumn{1}{|c|}{2004} & \multicolumn{1}{c|}{2006} & \multicolumn{1}{c|}{2008} \\
\hline Ataulfo & 14594 & 23577 & 31584 & 36243 \\
\hline Haden & 4247 & 24999 & 26188 & 24031 \\
\hline Keit & 4083 & 6033 & 6717 & 6525 \\
\hline Kent & 4695 & 10968 & 12768 & 13323 \\
\hline Manila & 37010 & 42136 & 44502 & 41049 \\
\hline Tommy Atkins & 5650 & 20248 & 20751 & 19521 \\
\hline Total & 161899 & 165873 & 172153 & 172284 \\
\hline
\end{tabular}

Fuente: Servicio de Información y estadística Agroalimentaria y Pesquera (SIAP). Anuario Estadístico de la Producción Agrícola de los Estados Unidos Mexicanos. Secretaría de Agricultura, Ganadería, Desarrollo Rural, Pesca y Alimentación. 1980-2008.

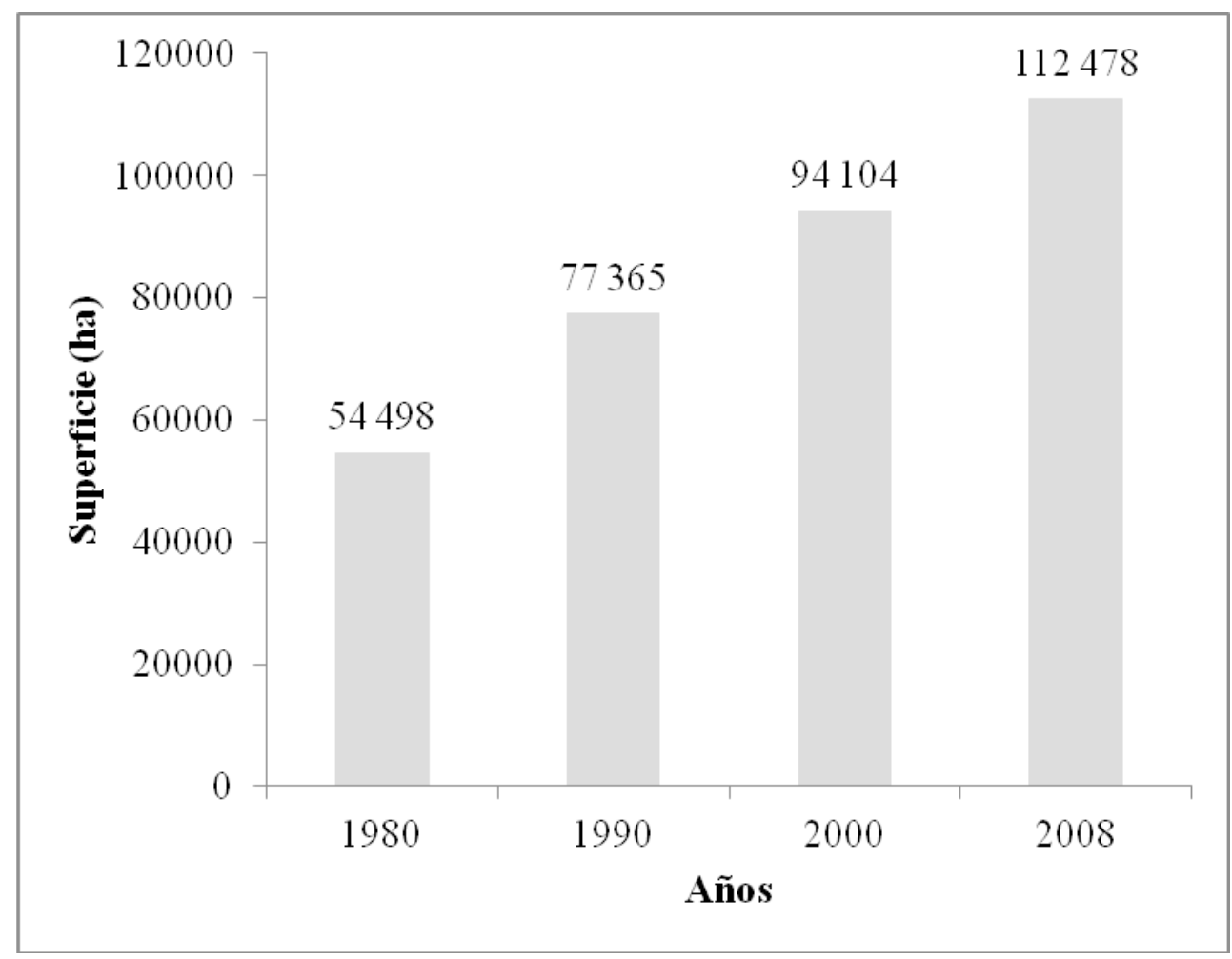

FIGURA 1- Evolución de la superficie cultivada con aguacate (Persea americana) en México (1980-2008). 


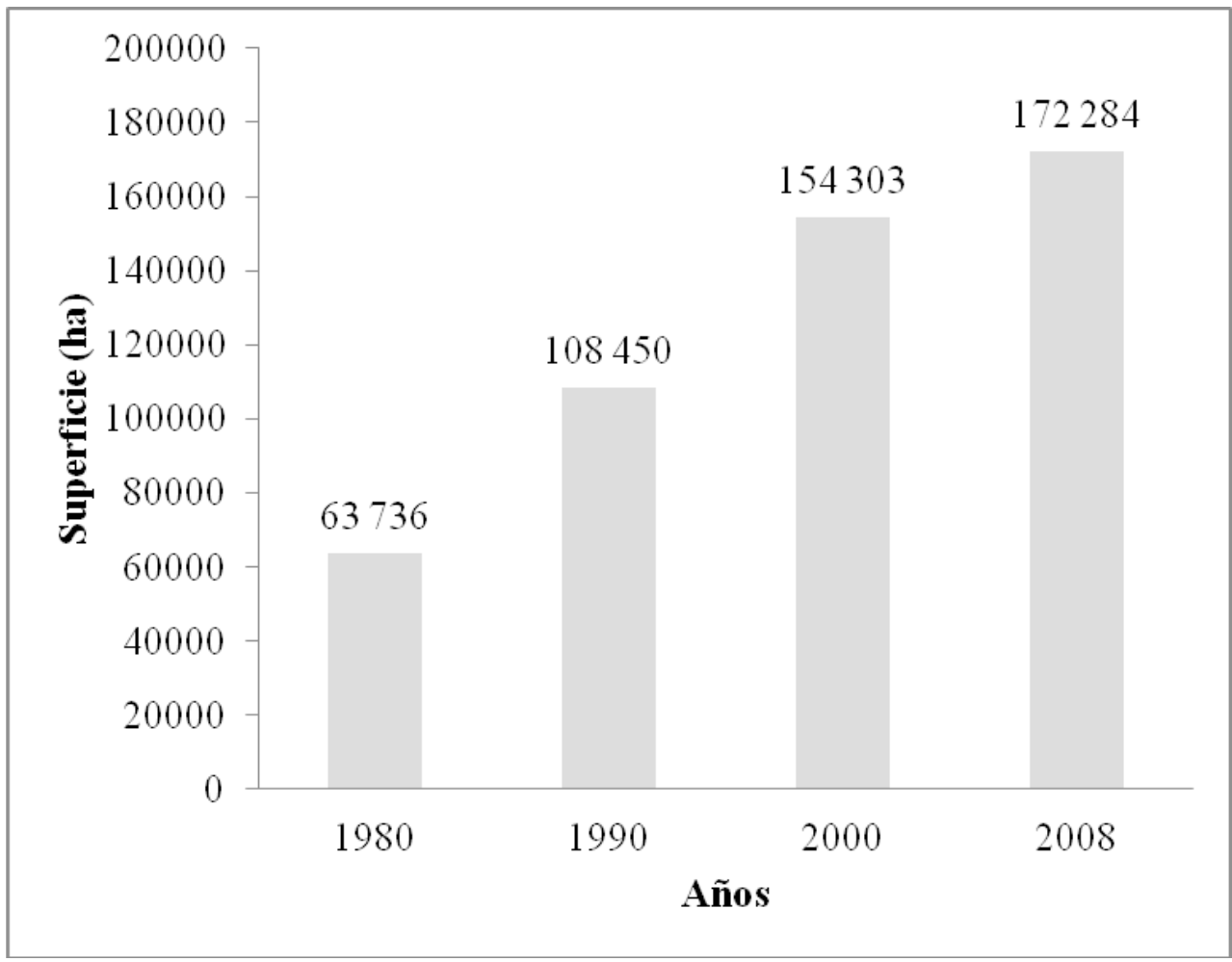

FIGURA 2 - Superficie cultivada con mango (Mangifera indica) en México (1980 - 2008)

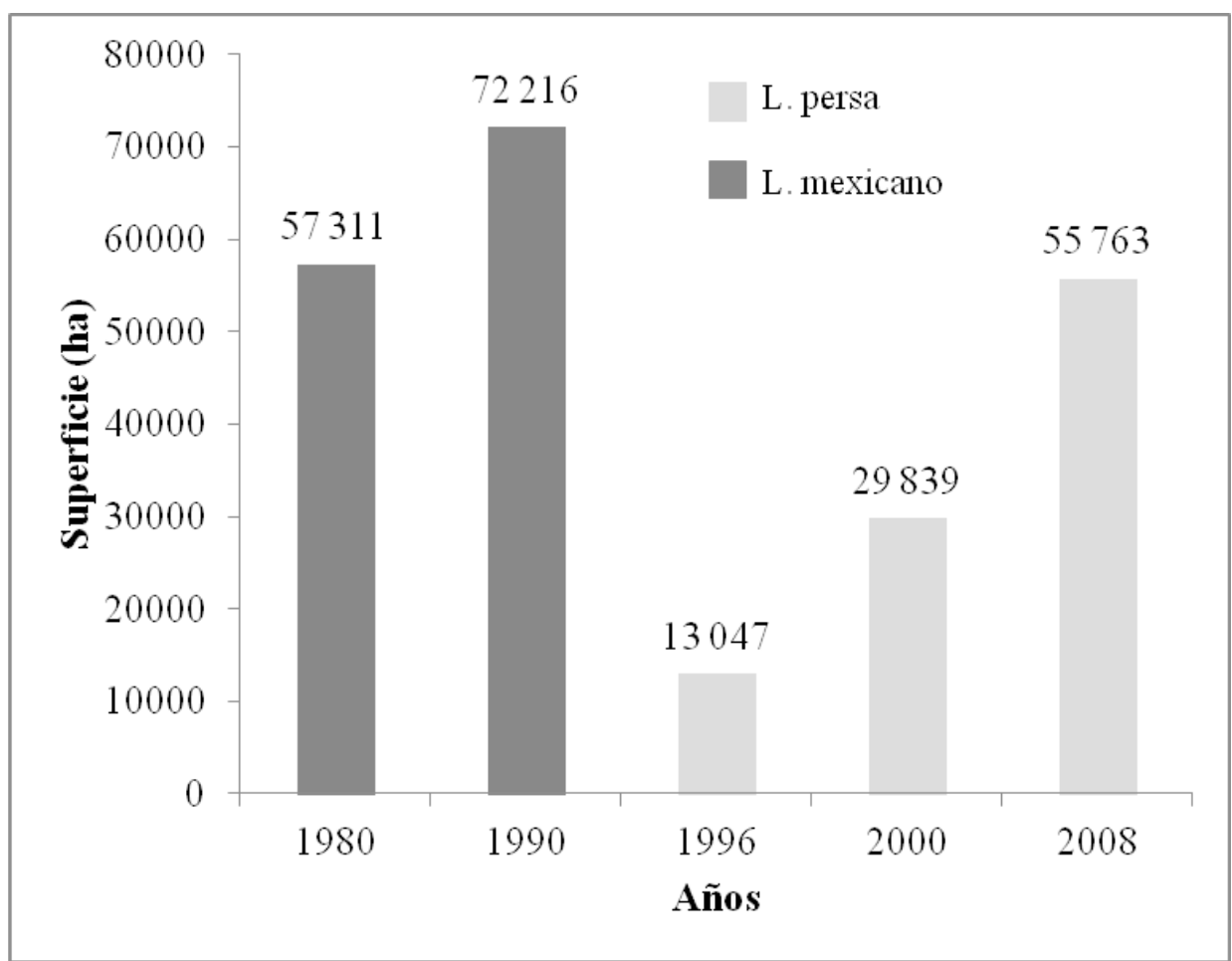

Figura 3 - Superficie cultivada con lima persa (C. latifolia) y limón mexicano (C. aurantifolia), en México $(1980-2008)$. 


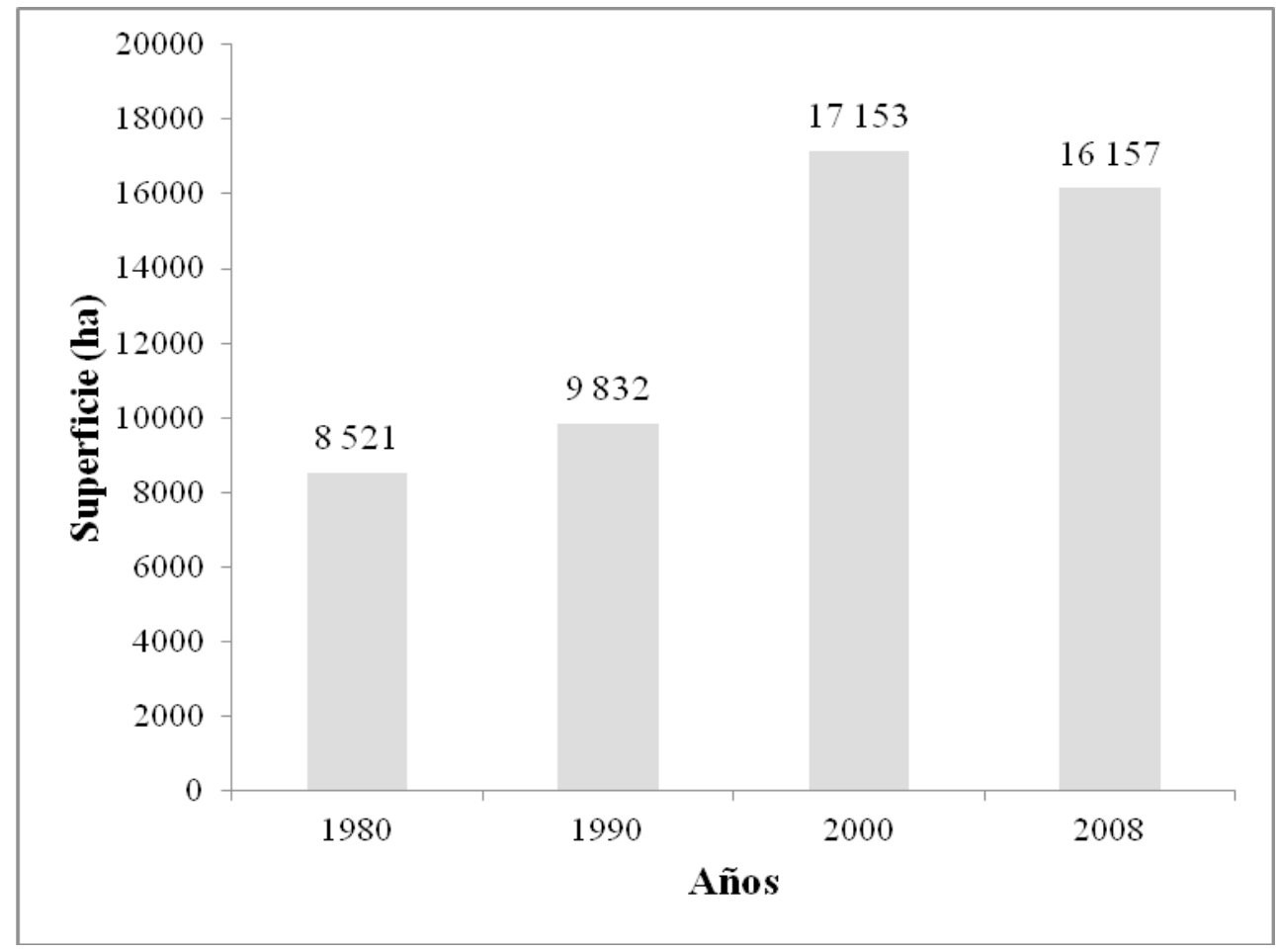

FIGURA 4 - Superficie cultivada con papayo (Carica papaya) en México (1980-2008).

\section{REFERENCIAS}

BORYS M. W. H. LESZCZYÑSKA-BORYS. EI potencial genético frutícola de la república mexicana. México: Fundación Sánchez Colín, CICTAMEX, 2001. 99 p.

CONABIO. Estrategia nacional sobre biodiversidad de México. México: Comisión Nacional para el Conocimiento y Uso de la Biodiversidad, 2000.

ENGELS J.M.M., A.W. EBERT, I. THORMANN, M.C. DE VICENTE. Centers of crop diversity and/ or origin, genetically modified crops and implications for plant genetic resources conservation. Genetic Resources and Crop Evolution, Dordrecht, v.53, p.1675-1688, 2006.

FAO. Conservación y utilización sostenible de los recursos fitogenéticos en América Central. In: INFORME DE LA REUNIÓN SUBREGIONAL SOBRE LOS RECURSOS FILOGENÉTICOS PARA AMÉRICA CENTRAL, 2., 1995. San Jose. Anexo...
HERNÁNDEZ BERMEJO J.E., J. LEÓN. Cultivos marginados. Otra perspectiva de 1492. Colección FAO: Producción y protección vegetal, Roma, n.26, p.3-44, 1992.

LÉPIZ I., R., E. RODRIGUEZ G. Los recursos fitogenéticos de México. In: MOLINA M. J.C. Y L; CÓRDOVA T. (Ed.) .Recursos fitogenéticos en México para la Agricultura y la Ganadería. Chapingo: Secretaria de Agricultura y Ganadería, Desarrollo Rural, Pesca y Alimentación y Sociedad Mexicana de Fitogenética, 2006. p.1-17. 20.

MEDINA G. G., J.A. RUIZ C., R. MARTÍNEZ P. Los climas de México. Guadalajara: INIFAP, 1998. 103 p. (Libro Técnico, 1)

RAMIREZ M. Redes de recursos filogenéticos en las Américas. Recursos Naturales y Ambiente, Cali, v.53, p.85-92, 2008.

RAMIREZ V.P.; BARRIOS L.C.; JIMENEZ, J.E., ZAVALA, G.F. Entorno de los recursos fitogenéticos en México. In: SIMPOSIUM APORTACIONES DE LA GENOTECNIA A LA AGRICULTURA. CHAPINGO, 2003, México. Memoria... Chapingo: Sociedad Mexicana de Fitogenética, 2003. p.58-87. 
RIVERA-CABRERA F.; PONCE-VALADEZ, M.; DÍAZ de LEÓN SÁNCHEZ, F.; VILLEGASMONTER, A.; PÉREZ-FLORES, L.J. Acid limes: a review. In: TEIXEIRA, J.A.S. (Ed.). Fresh produce 4. Japan: Global Science Bocks, 2010. p.116-122. Special Issue 1.

RZEDOWSKI, J. La vegetación de México. México: Ed. LIMUSA, 1998. 341 p.

SENASICA - Servicio Nacional de Sanidad, Inocuidad y Calidad Agroalimentaria. 2010. Disponible en: $<$ www.senasica.gob.mx>. Acesso en: 14 jun. 2011. SIAP - Servicio de Información y estadística Agroalimentaria y Pesquera. Anuario estadístico de la producción agrícola de los Estados Unidos Mexicanos. México: Secretaría de Agricultura, Ganadería, Desarrollo Rural, Pesca y Alimentación, 2010. Disponible en: <http://www.siap.gob.mx>. Acesso en: 06 jun. 2011.
TELIZ-ORTIZ, D.; MARROQUÍN PIMENTEL, F.J. Importancia histórica y socioeconómica del aguacate. In: TELIZ-ORTIZ, D.; MORA, A. (Ed.). El Aguacate y su manejo integrado.2.ed. México. Mundi Prensa México, 2007. p.3-27

VILLEGAS - MONTER, A. Situación y perspectivas del cultivo de mango en México. In: JORNADA DE TRANSFERENCIA DE TECNOLOGÍA PARA EL CULTIVO DEL MANGO, 2., 2007. Memoria... Sinaloa: Fundación Produce Sinaloa, 2007. p.51-58.

VILLEGAS-MONTER A.; CURTÍ - DÍAZ, S.A. Situación de la citricultura en México. In: SEMINARIO INTERNACIONAL DE POST-COSECHA DE CÍTRICOS, 2., 2005, Concordia. Actas... 2006, p.7-14. 